\title{
Simulation of the Condensation and Fractionation Unit in Waste Plastics Pyrolysis Plant
}

\author{
Roman Krzywda ${ }^{1}\left[\right.$ B Bogumiła Wrzesińska ${ }^{1}$ (])
}

Received: 20 June 2019 / Accepted: 2 March 2020 / Published online: 6 March 2020

(c) The Author(s) 2020

\begin{abstract}
The condensation and fractionation unit design affects the quantity and quality of the liquid products derived from the waste plastics pyrolysis. The oil products, if meet the standards requirements, can be used as an alternative fuel. Three configurations of this unit were studied: two condensers system with phase separators (2 CNDR), three condensers system with phase separators (3 CNDR) and as an unconventional solution in pyrolytic plant—-the rectification column system (TOWR). Based on the chromatographic analysis and laboratory distillation results of the pyrolytic oil from industrial plant, the composition of the model oil was determined. This model oil was then used in simulations of the condensation and fractionation units, using ChemCad software. The comparison of the three tested configurations showed that the best separation of components was achieved in the TOWR system. Although in the simplest CNDR 2 system the desired heavy fraction yield was higher, its composition was least favourable in terms of oil properties (e.g., flash point), because more light components were condensed. Since the application of rectification column resulted in the best fractionation efficiency, the proposed TOWR configuration was examined in detail. The change of the rectification column process parameters (mainly the reflux ratio) allows for precise control of the oil fractions composition. The reflux ratio, and hence the distillate temperature, determines the heavy fraction yield. The yield and composition of the oil fractions practically do not depend on the feed stream temperature. By increasing the number of stages in the rectification column the separation of near-boiling components is improved, but the significant effect is noticeable only up to 10 theoretical stages.
\end{abstract}

\section{Graphic Abstract}

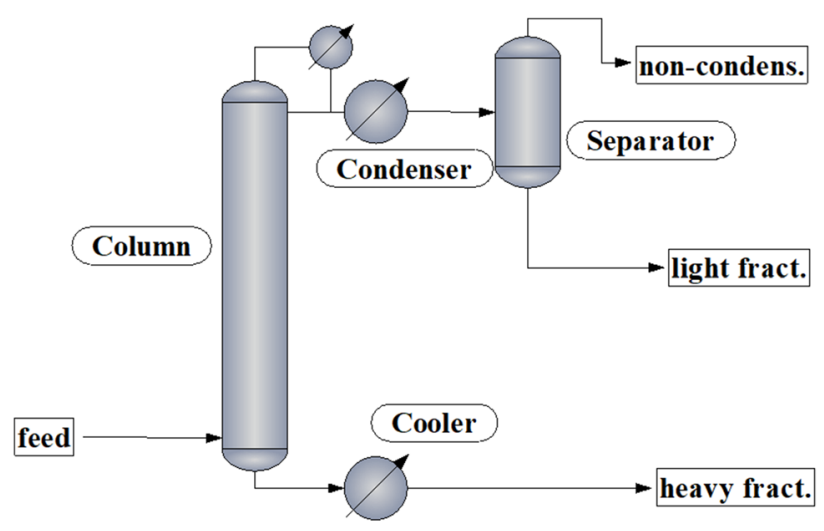

Keywords Pyrolysis plant $\cdot$ Plastics waste $\cdot$ Pyrolytic oil $\cdot$ Fractionating column $\cdot$ Condensation unit simulation

Roman Krzywda

Roman.Krzywda@pw.edu.pl

Extended author information available on the last page of the article 


\section{Statement of Novelty}

Pyrolysis, as well as other thermochemical conversion processes e.g. hydrothermal liquefaction, is an intensively developed method of waste plastics recycling. Typical industrial installations use simple solutions of the post-pyrolytic products condensation plant with a limited possibility to control the oil parameters. The paper proposes a new approach to this problem by the use of an innovative configuration of the fractionation and condensation unit with a rectification column supplied by the wax-free post-pyrolytic vapour. This solution allows to control the oil composition in order to meet the requirements for market products (eg. heating oil) and reduction of energy consumption. Based on the parameters of pyrolytic oil from the industrial plant, the model oil composition was found. Then the ChemCad software was used to process simulations and compare three configurations of the condensation and fractionation system.

\section{Introduction}

Global production of plastics (not included polyethylene terephthalate PET, polyamide PA and polyacryl-fibers) reached 348 million tonnes in 2017 [1]. Asia (50.1\%) is the largest producer of plastic materials, followed by Europe (18.5\%) and North American Free Trade Agreement "NAFTA" (17.7\%).

Due to their versatility, plastics have become important materials in strategic sectors such as packaging, building \& construction, transportation, renewable energy, agriculture, medical devices or sports. The plastic products have a lifespan from less than 1 year to more than 50 years, but more than $40 \%$ of plastics are used for less than a month meaning that significant volumes of waste are generated annually [2]. At the end of their life, plastics are still very valuable resources that can be converted mechanically or chemically into new feedstock or into energy.

Pyrolysis, i.e. thermal decomposition under anaerobic conditions in high temperature (usually $350-800{ }^{\circ} \mathrm{C}$ ), is an alternative to classical plastics waste management methods [2-4]. During this process, chemical bonds in the polymer chains are cracked and hydrocarbons with relatively short chains are formed [5]. Pyrolysis has a significant advantage over other recycling processes, as it does not require an intensive sorting process, except for PET and polyvinyl chloride (PVC) removal. Moreover, plastics can be contaminated with bio-waste, which makes this method particularly useful for recycling polyolefin fraction of municipal waste.

Compared to another promising thermal degradation method, i.e. hydrothermal liquefaction (HTL), which requires a pressure of 5-20 $\mathrm{MPa}$, pyrolysis is usually carried out at atmospheric pressure.

The end products of the process are pyrolytic oil, waxes, non-condensing gas and char. Process parameters, such as temperature, type of reactors, pressure, residence time, catalyst, play major role in in optimizing the yield and composition of individual product [6-8].

Oil is the most valuable product of waste plastics pyrolysis. However, the low quality of raw oil limits its direct applications $[9,10]$. The essential problem with the use of liquid pyrolytic products as diesel or heating oil is to meet the requirements of quality standards. National regulations specify the physicochemical properties of fuels and the content of various pollutants, both in the oil itself and in the exhaust gas.

For commercial use the oil needs upgrading procedure which depends on its targeted application. Processing of the oil using various post-treatment methods such as distillation, filtration, dewatering, hydrotreatment [11] is often required to make it suitable as a transport or heating fuel.

Usually oil is obtained as the two fractions: light and more desirable heavy, with properties similar to diesel or heating oil.

Vapor stream leaving the pyrolysis reactor is a complex mixture mainly of olefinic, paraffinic, naphthalene and aromatic hydrocarbons with a wide boiling temperature range [6]. Therefore, this stream can be divided into desired fractions by fractional condensation in a series of condensers with phase separators. At each stage of condensation, partial vapor condensation occurs, based on differences in the volatility of the components. The use of a rectification column, in which liquid-vapor equilibrium is repeatedly established at subsequent stages, improves the fractionation of the components.

The aim of the work was to examine the ability of controlling of the both fractions composition by selecting the appropriate equipment and process parameters in the post-pyrolysis condensation unit. The appropriate oil fractionation in the condensation system will avoid costly distillation in further refining procedure.

Analysis of the literature sources shows that most pyrolysis studies are carried out on a laboratory scale [6]. There is a small amount of data based on industrial installations [2]. From the analysis of industrial plants offered on the market, it is known that most of them have simple condensation systems based on various types of heat exchangers. The authors' experience shows that the process and equipment solutions used in the oil condensation unit affect the quality of the products obtained. In order to improve the process, it seems beneficial to use simultaneous fractionation and condensation using a rectification column. Before this solution implementation on an industrial scale, it was 
necessary to analyse the effectiveness of such a process using computer simulation.

\section{Problem Description and Formulation}

The mixture of hydrocarbons formed in the pyrolysis of polyolefinic wastes is characterized by a wide range of fractions. It contains a high concentration of heavy paraffinic hydrocarbons with boiling point above $300{ }^{\circ} \mathrm{C}$, responsible for the relatively high melting point of the generated product. On the other hand, the high content of low-boiling fractions is responsible for low flash point value. Thus, the raw pyrolytic oil does not meet the requirements for market products eg. heating oils and requires further processing. The post-pyrolytic installation should enable fractionation the vapour stream from the pyrolytic reactor into the following:

- paraffinic (wax) fraction,

- heavy oil fraction with properties similar to heating oil (main product),

- light oil fraction with properties similar to technological gasolines,

- non-condensing gases.

Condensing waxes block the heat transfer surface. When designing the condensation and fractionation unit, it was assumed that the first paraffinic fraction is removed in wax separator, placed between the reactor and the condensation unit, so the processing gas is wax-free.

In most existing technologies, system of condensers and separators is used to fractionate the next three fractions. The heavy oil obtained in such a system, often does not meet the requirements of the relevant standards for market products, especially the flash point, and it requires further processing, e.g. by distillation [12]. Such solution needs re-evaporation of hydrocarbons, which involves considerable expenditure of energy, investment (the need to build additional process line) and related costs of operation and maintenance of the system.

Therefore, an alternative solution with rectification column fed directly by wax-free post-pyrolytic vapour was proposed.

\section{Methodology}

Three concepts of the fractionation and condensation unit of gaseous products derived from the waste plastics pyrolysis were compared. Based on the parameters of pyrolytic oil from the industrial plant, the ChemCad software (Chemstations Inc.) was used to process simulations. The processing scheme is shown in Fig. 1.
It was assumed that gas leaving the pyrolysis reactor is supplied to the condensation unit and a waxes separator is placed between the reactor and the unit, hence the gas is wax-free.

As is known, the pyrolytic gas consists of several hundred chemical compounds, mainly and olefins, paraffins, naphthenes and aromatics [6]. The proper assumption of the model gas composition used for the calculation was thus an important problem. Model must represent the gas from the real industrial installation, but at the same time make the computer simulation possible. For technical reasons, the direct analysis of the pyrolytic gas chemical composition is difficult, so oil obtained after its condensation was used for this purpose. The pyrolytic oil composition was analysed by chromatographic methods.

At the same time experimental fractional distillation of this oil was carried out to obtain the distillated fraction dependence on temperature.

Based on the chromatographic analysis, 25 key oil components were selected, and their concentrations were estimated. Next, a simulation of periodic distillation was carried out for that composition. The obtained distillation curve for the model oil was then compared to the experimental data. Since the both distillations data, were not strictly the same, the concentrations of individual components were slightly modified and subsequent simulations of periodic distillation were made to fit simulation results to experiments.

After determining the final model oil composition, propane representing non-condensing gases was added. In this way, the model composition of the inlet vapour stream to the condensing unit was defined.

In the next step, the flowsheets of three condensation systems were prepared and simulations for various process parameters were carried out.

\section{Model Oil Composition}

\section{Chromatographic Analysis}

Quality analysis of pyrolytic oil was performed using GC6890N gas chromatograph (Agilent Technologies), combined with mass detector MS 5973N and column RESTEK Rxi-1ms (length $30 \mathrm{~m}$, internal diameter $0.25 \mathrm{~mm}$, film thickness $0.25 \mu \mathrm{m}$ ). The temperature of the injection chamber was $250{ }^{\circ} \mathrm{C}$. The furnace program was as follows: initial temperature $60{ }^{\circ} \mathrm{C}$, heating rate $10^{\circ} \mathrm{C} / \mathrm{min}$ to $320^{\circ} \mathrm{C}$. The carrier gas was helium, flowing through the column at a rate of $1 \mathrm{~mL} / \mathrm{min}$. A split 60:1 was used.

For quantitative chromatographic analysis a Shimadzu GC-2014 gas chromatograph with a flame ionization detector (FID) was used. Chromatographic analysis was carried out in the Zebron Inferno ZB-5HT capillary column 
Fig. 1 Procedure for obtaining input data for simulations of the fractionation and condensation units, based on pyrolytic oil analysis

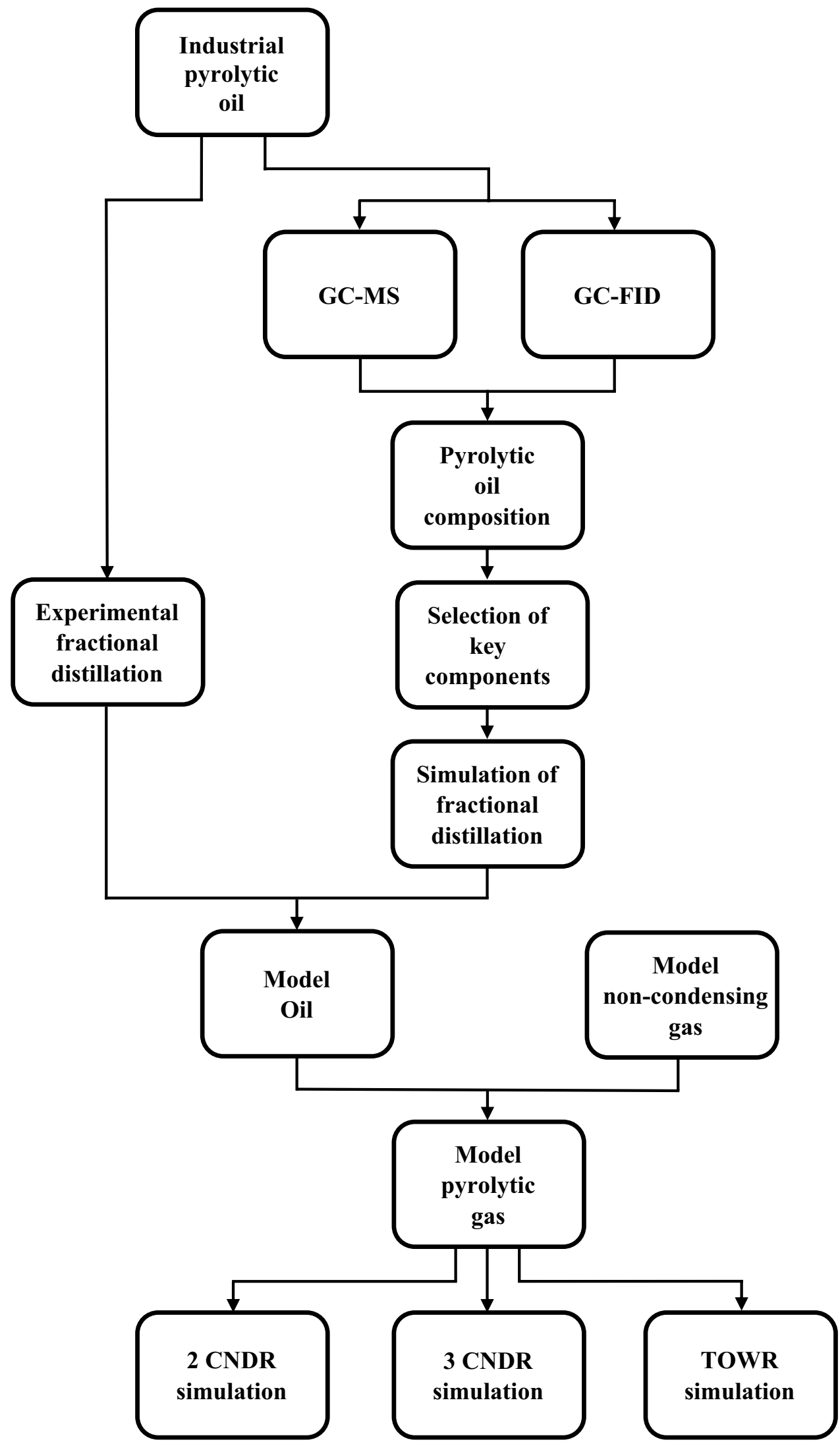


by Phenomenex (30 m long, $0.25 \mathrm{~mm}$ internal diameter, $0.1 \mu \mathrm{m}$ film thickness), which is dedicated for petrochemical applications. The GC conditions were as follows: split injection mode 50:1; nitrogen carrier gas flow rate $0.31 \mathrm{~mL} /$ min; column temperature programmed from 50 to $330{ }^{\circ} \mathrm{C}$ at $3{ }^{\circ} \mathrm{C} / \mathrm{min}$, initial time $5 \mathrm{~min}$, final time $10 \mathrm{~min}$. Detector temperature was $350{ }^{\circ} \mathrm{C}$. The GC-FID chromatogram is shown in Fig. 2.

The selected hydrocarbon peaks were identified by comparing the retention time of the reference standards in the same condition. Quantitative analysis for those hydrocarbons was performed using the external standard method. The calibration curve for benzene, toluene and xylenes was developed based on available standards (ChemPur reagents). Other compounds were identified by direct comparison with the GC-MS chromatogram. This procedure may contain some errors in the identification, as both analyses were made under different conditions (columns, temperature profile, etc.), nevertheless the locations of the largest peaks or groups of peaks on both chromatograms were similar. It can therefore be concluded that the positions of the corresponding peaks were very likely to be matched.

The percentage of individual hydrocarbons was calculated in relation to total area of the GC-FID chromatogram. Although a direct comparison of the peak areas to determine the sample composition suffers from many drawbacks, it has been the most used technique for analysing the complex mixture of compounds.

Based on GC-MS chromatogram, 25 representative hydrocarbons for model oil were selected. When selecting compounds, both the peak area and the probability of identification were considered. At the same time, it was checked whether the compound is present in the ChemCad Component Database. In all cases, except for one 2, 4-dimethylhepten, which was added to the database, the hydrocarbons were available in the database.

To make the quantitative results more representative, the entire GC-FID chromatogram was divided into 25 regions around the selected main peaks and the areas of adjacent peaks were added to the area of the selected peaks. In this way, all 477 peaks were included in the model oil composition calculation.

Finally, the initial composition of the model oil for simulation of fractional distillation was defined.

\section{Experimental Distillation}

The wax-free oil from the mixed plastics wastes derived from industrial pyrolysis plant was used for experimental distillation. The raw material for this plant was the mixed

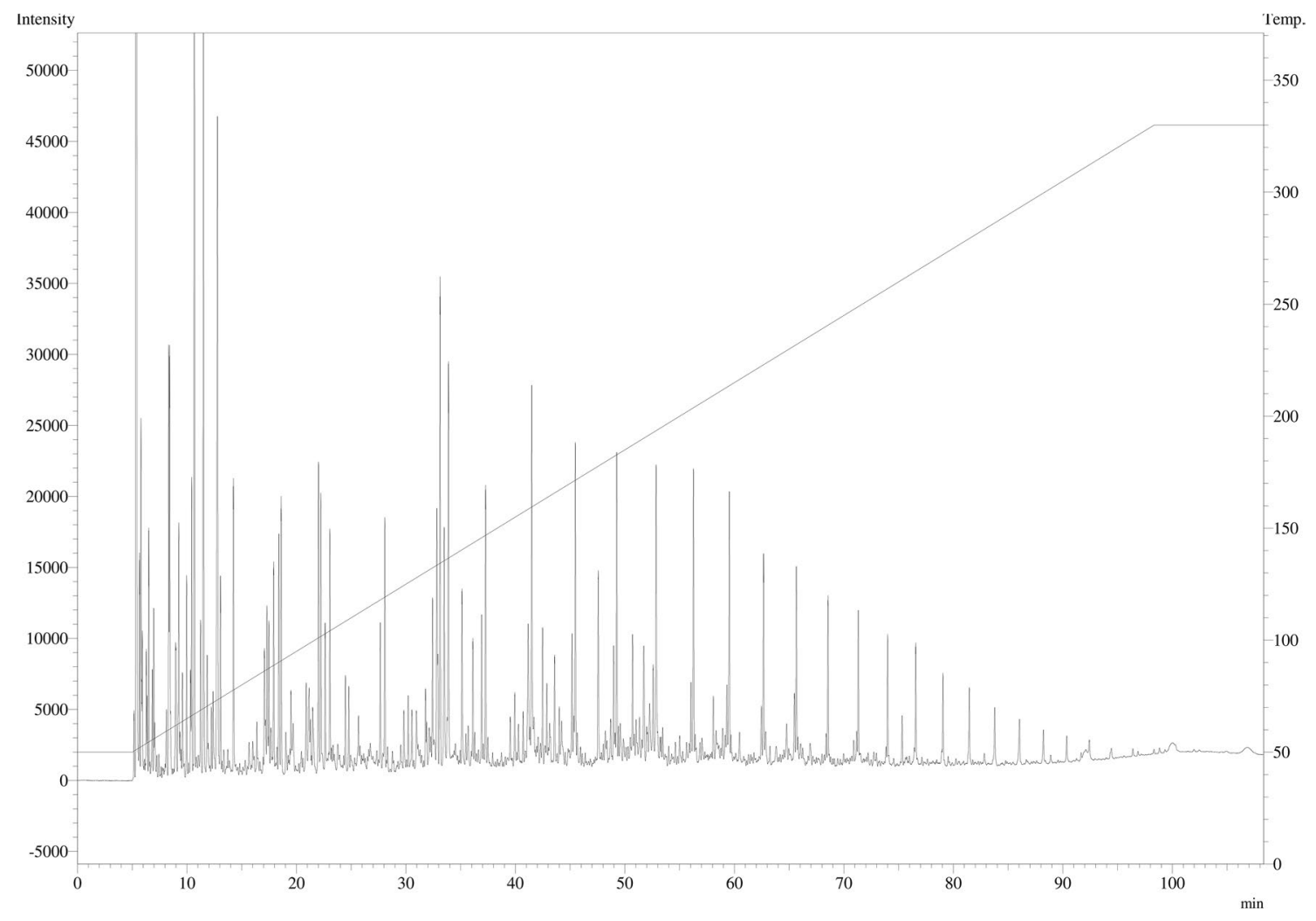

Fig. 2 Gas chromatographic analysis GC-FID of the pyrolytic oil derived from the waste plastics 
waste plastics from the selective collection of municipal waste from Poland, free of PET and PVC, containing mainly polypropylene and polyethylene.

The oil density was $791 \mathrm{~kg} / \mathrm{h}$ and the viscosity 1.4 $\mathrm{mm}^{2} / \mathrm{s}$ at $40{ }^{\circ} \mathrm{C}$. Four series of fractional distillation at atmospheric pressure were carried out in a glass set. The sample volume was $500 \mathrm{~mL}$. The dependence of the fraction distillated on the vapour temperature was obtained (Fig. 3).

\section{Batch Distillation Simulation}

Fractional distillation simulations were carried out using the ChemCad Batch Distillation Column. For a simple batch distillation two stages (including the condenser and the reboiler) and a reflux ratio of zero were specified. UNIFAC was chosen as global K-value model and Latent Heat as global enthalpy model. Assumed pot charge was $1000 \mathrm{~kg}$, and distillate mass rate $200 \mathrm{~kg} / \mathrm{h}$.

In the first simulation run, the composition of the pot charge was based on chromatographic analysis of the oil from the industrial plant, as described in "Chromatographic Analysis" section.

As a result of the calculations, a dependence of the vapour temperature on the degree of distillation was generated. This function was compared to the laboratory distillation data. Then in the next steps, the concentrations of individual hydrocarbons in model oil were slightly modified to adjust the simulated distillation curve of the model oil as close as possible to the experimental data. Final composition of the model oil is presented in Table 1 and the comparison of simulation results with experimental data in Fig. 3.

To illustrate the periodic distillation simulation, mass change of a few oil components in the pot is shown in Fig. 4.

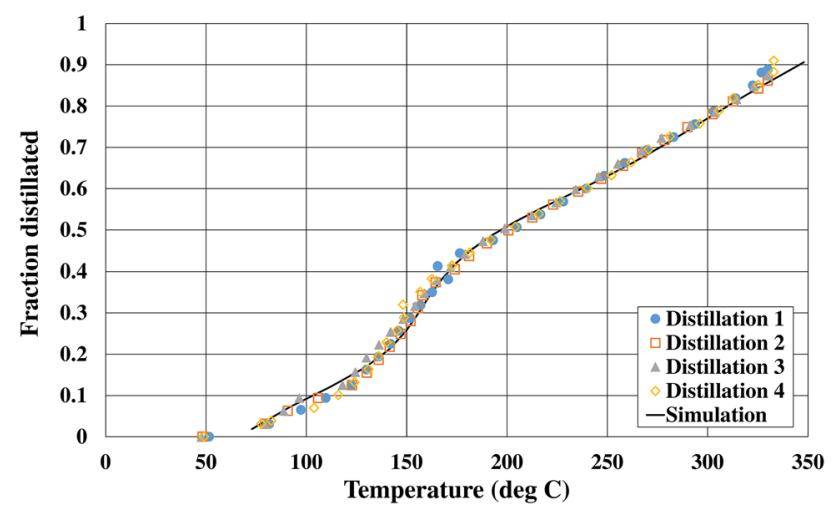

Fig. 3 Comparison of the 4 experimental series of periodic distillation of pyrolytic oil with simulation results of model oil distillation

\section{Condensation and Fractionation Unit Simulations}

Three different pyrolytic gas condensation and fractionation systems in pyrolysis plant were simulated:

- 2 CNDR-two condensers system with phase separators,

- 3 CNDR-three condensers system with phase separators,

- TOWR-rectification column system.

The inlet vapour stream for all above installations was a combination of model oil (Table 1) and propane representing non-condensable gases. According to data from the plastics pyrolysis plant, the production yield of noncondensing gas is about $15 \%$ of the oil output. Therefore, it was assumed that the feed stream flow rate, for computational purposes equal to $1150 \mathrm{~kg} / \mathrm{h}$, is the sum of $1000 \mathrm{~kg} / \mathrm{h}$ of oil and $150 \mathrm{~kg} / \mathrm{h}$ of propane.

Since a wax separator, in which the highest boiling hydrocarbons condense, was located between the pyrolysis reactor and the condensation and fractionation unit, the inlet stream temperature to the unit was assumed to be $300{ }^{\circ} \mathrm{C}$. In addition, calculations for temperatures of 250 and $350^{\circ} \mathrm{C}$ were carried out for the TOWR system.

The main product is a heavy fraction of pyrolytic oil. For commercial use, as heating oil, it must meet the requirements of the relevant standards. The flash point, which is a general indication of the flammability or combustibility of a liquid, is one of the important parameters. According to the Polish standard (PN-C-96024:2011) flash point of heating oil should not exceed $56{ }^{\circ} \mathrm{C}$.

Fractionation of pyrolytic oil should therefore lead to obtain high yield of heavy fraction of high commercial value. Due to the important parameter, which is the flash point, it is also crucial to remove from it the most flammable components. In the model oil, hydrocarbons with flash point above and below the limit value are $n$-Decane and $n$-Undecane (Table 1). Therefore, there should be a good separation of these components.

\section{Case 1-2 CNDR}

The simplest configuration of the condensation and fractionation system consists of 2 sets of condensers combined with liquid and gas phase separators. In the first condenserseparator unit, heavy oil is separated. The calculations were carried out for vapour inlet stream at $300{ }^{\circ} \mathrm{C}$ and the condensation temperature range $110-170{ }^{\circ} \mathrm{C}$. Heavy oil is then cooled to an ambient temperature of $20{ }^{\circ} \mathrm{C}$. 
Table 1 Compounds of the model oil

\begin{tabular}{|c|c|c|c|c|c|c|}
\hline No. & Name & Chemical formula & $\begin{array}{l}\text { Molar } \\
\text { mass (g } \\
\left.\mathrm{mol}^{-1}\right)\end{array}$ & $\begin{array}{l}\text { Normal } \\
\text { boiling point } \\
\left({ }^{\circ} \mathrm{C}\right)\end{array}$ & $\begin{array}{l}\text { Flash } \\
\text { point [13] } \\
\left({ }^{\circ} \mathrm{C}\right)\end{array}$ & $\begin{array}{l}\text { Concentra- } \\
\text { tion ( } \% \\
\text { mass) }\end{array}$ \\
\hline 1 & Pentane & C5H12 & 72.2 & 36.1 & -40 & 0.68 \\
\hline 2 & 2-methyl-1-pentene & C6H12 & 84.2 & 62.1 & -27 & 0.58 \\
\hline 3 & Benzene & C6H6 & 78.1 & 80.1 & -12 & 0.27 \\
\hline 4 & Toluene & $\mathrm{C} 7 \mathrm{H} 8$ & 92.1 & 110.6 & 6 & 0.55 \\
\hline 5 & 4-Methylheptane & C8H18 & 114.2 & 117.7 & 6 & 0.05 \\
\hline 6 & 3-Ethylhexane & C8H18 & 114.2 & 118.5 & 11 & 0.07 \\
\hline 7 & 2, 4-Dimethyl-1-Heptene & С9H18 & 126.2 & 137.3 & - & 0.35 \\
\hline 8 & P-Xylene & $\mathrm{C} 8 \mathrm{H} 10$ & 106.2 & 138.4 & 27 & 3.02 \\
\hline 9 & Styrene & $\mathrm{C} 8 \mathrm{H} 8$ & 104.2 & 145.2 & 31 & 2.52 \\
\hline 10 & $n$-Nonane & $\mathrm{C} 9 \mathrm{H} 20$ & 128.3 & 150.8 & 30 & 8.56 \\
\hline 11 & $n$-Decane & $\mathrm{C} 10 \mathrm{H} 22$ & 142.3 & 174.2 & 46 & 4.90 \\
\hline 12 & $n$-Undecane & $\mathrm{C} 11 \mathrm{H} 24$ & 156.3 & 195.9 & 65 & 6.39 \\
\hline 13 & $n$-Dodecane & $\mathrm{C} 12 \mathrm{H} 26$ & 170.3 & 216.3 & 74 & 2.84 \\
\hline 14 & $n$-Tridecane & C13H28 & 184.4 & 235.5 & 91 & 5.32 \\
\hline 15 & $n$-Tetradecane & C14H30 & 198.4 & 253.6 & 100 & 4.52 \\
\hline 16 & $n$-Pentadecane & C15H32 & 212.4 & 270.8 & 132 & 5.93 \\
\hline 17 & $n$-Hexadecane & C16H34 & 226.5 & 286.9 & 135 & 5.83 \\
\hline 18 & $n$-Heptadecane & C17H36 & 240.5 & 302.2 & 149 & 5.93 \\
\hline 19 & n-Octadecane & C18H38 & 254.5 & 316.7 & 165 & 4.62 \\
\hline 20 & $n$-Nonadecane & C19H40 & 268.5 & 329.9 & 168 & 4.43 \\
\hline 21 & $n$-Eicosane & $\mathrm{C} 2 \mathrm{OH} 42$ & 282.6 & 343.8 & 182 & 4.92 \\
\hline 22 & $n$-Heneicosane & $\mathrm{C} 21 \mathrm{H} 44$ & 296.6 & 356.5 & $>113$ & 4.02 \\
\hline 23 & $n$-Docosane & $\mathrm{C} 22 \mathrm{H} 46$ & 310.6 & 368.6 & $>113$ & 6.83 \\
\hline 24 & $n$-Tricosane & C23H48 & 324.64 & 380.2 & $>113$ & 7.83 \\
\hline 25 & $n$-Tetracosane & C24H50 & 338.66 & 391.3 & $>113$ & 9.04 \\
\hline
\end{tabular}

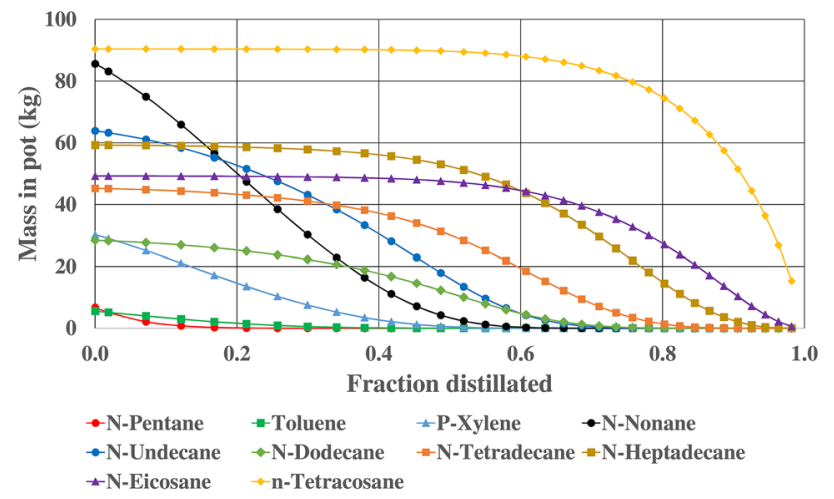

Fig. 4 The dependence of the mass of selected components in the pot on the fraction distillated

The vapours from the first separator are directed to the second condenser-separator set, in which the light fraction is separated. The assumed final temperature is $20^{\circ} \mathrm{C}$. The non-condensable gases are the third stream. The flowsheet of the studied process can be seen in Fig. 5.
The thermodynamic data for the components were adapted from the ChemCAD database. The simple heat exchanger unit HTXR in design mode was selected to simulate the condensers and the cooler. The multipurpose flash unit FLAS in isothermal mode was used as phase separator. The temperature in the flash unit was set to the same value as the outlet temperature from the condenser.

Due to the different assumed heavy oil condensation temperatures, the flowsheet was calculated several times, with changes in the initial data for every simulation.

\section{Case 2-3 CNDR}

The second system was studied by applying a process model analogous to the one proposed in the first case. In this case, an additional condensation step was used (Fig. 6). The heavy fraction was partially condensed in the condenser 1 and the rest in the condenser 2 . These two streams were then mixed together, using stream mixer module MIXE. First condenser outlet temperature was equal to the temperature of the bottom product from rectification column, described in case 3 . The condensation temperature in the second condenser was 
assumed, as in the first case, in the range $110-170^{\circ} \mathrm{C}$. The rest of the diagram was identical to the first version.

The use of two-stage condensation of heavy fraction results from technical reasons in industrial installations. Heavy hydrocarbons with the highest boiling point that condense first may cause fouling of the cooling surface. Hence, in the first stage, easy-to-clean heat exchangers with large clearances are used, e.g. a pipe in a pipe. In the next stage more sophisticated constructions with large heat exchange surfaces are used.

\section{Case 3-TOWR}

The technological diagram of the third system, shown in Fig. 7, consisted of a rectifying column, light oil fraction
Fig. 5 The flowsheet of 2 CNDR condensation and fractionation system

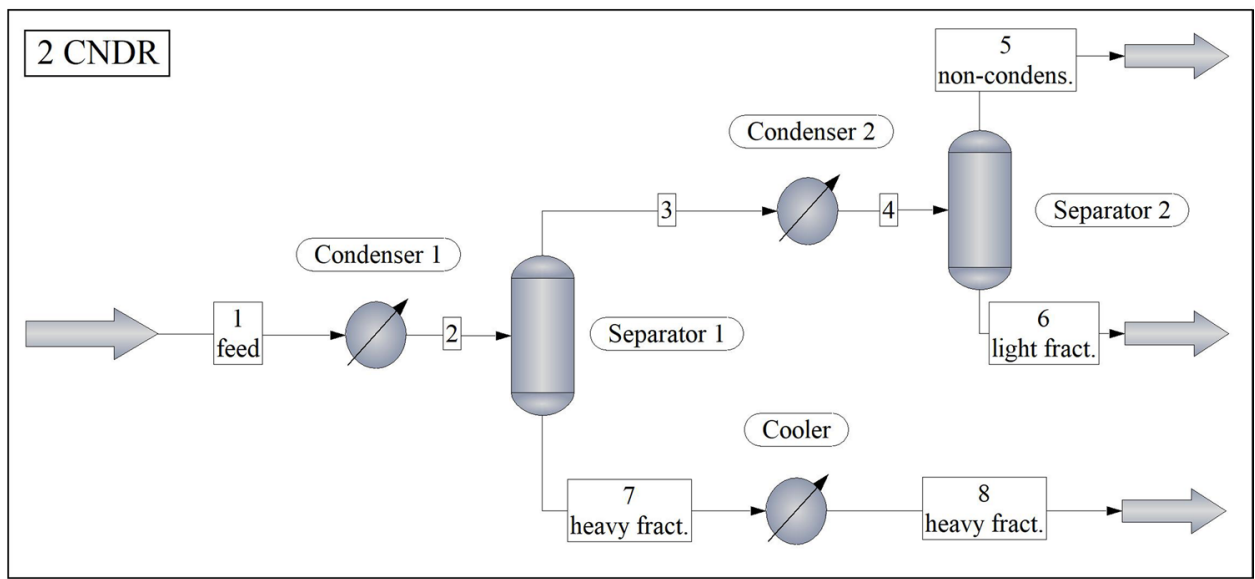

Fig. 6 The flowsheet of 3 CNDR condensation and fractionation system

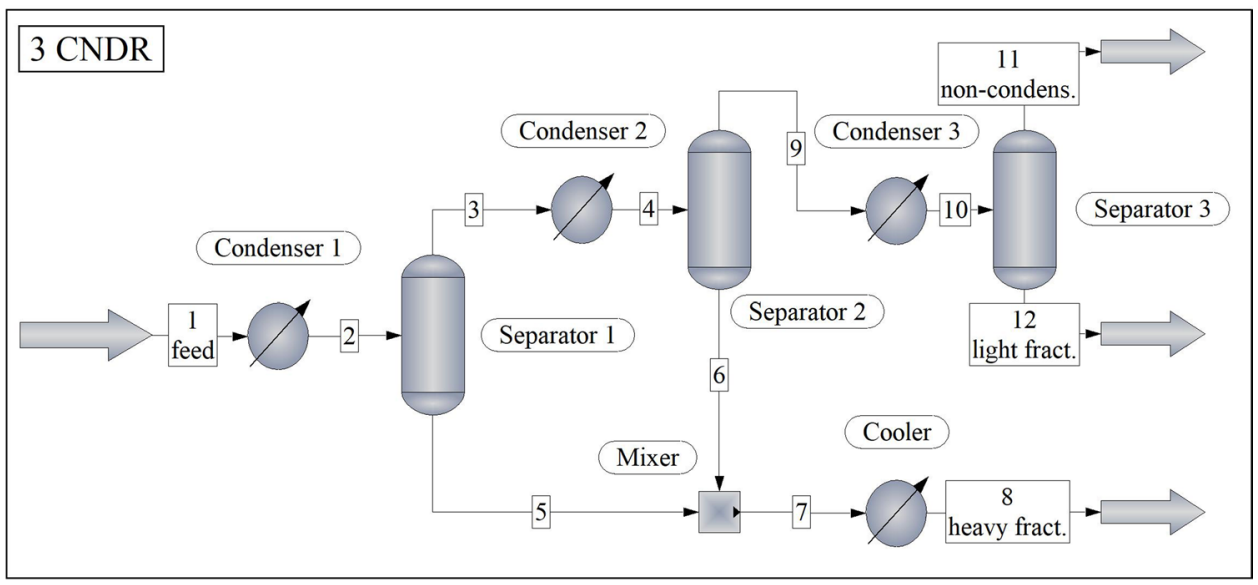

Fig. 7 The flowsheet of TOWR condensation and fractionation system

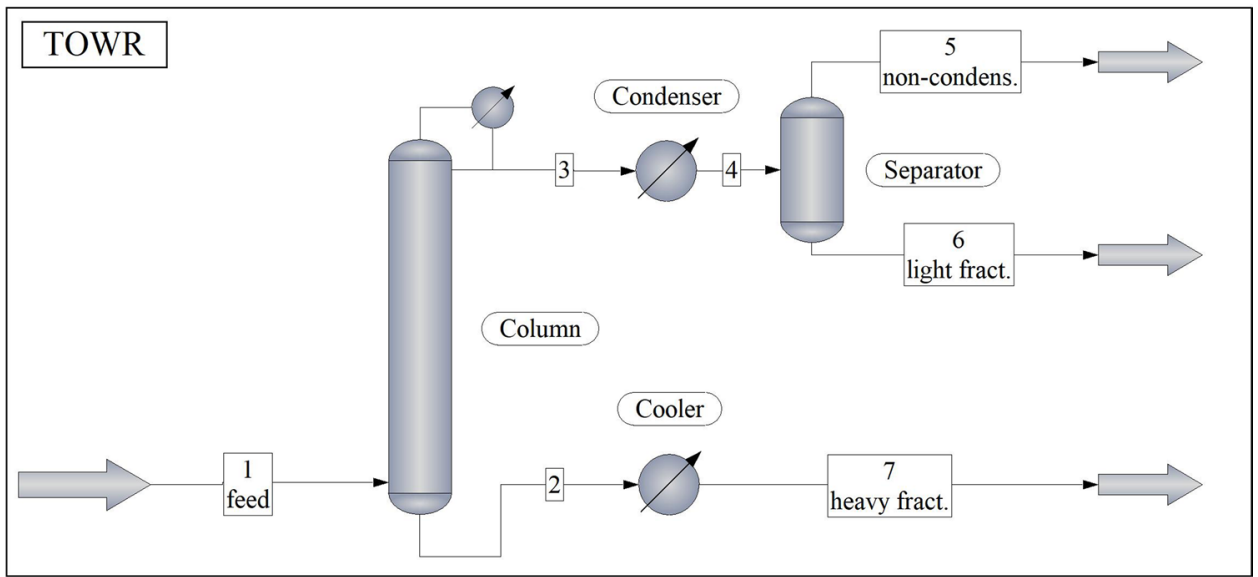


condenser combined with phase separator and heavy oil cooler.

A multi-stage vapour-liquid equilibrium module TOWR, which simulates any single column calculation including distillation columns, was applied to model rectifying column. The thermodynamic settings were the same as in the periodic simulation in "Batch Distillation Simulation". The distillation was carried out at atmospheric pressure. The column had a partial condenser and the vapour from the condenser was defined as a distillate. "No reboiler" mode was selected, and the feed stream entered the column in a lowest location. The distillate temperature was used as a variable to the condenser mode specification. This parameter can be easily measured and used as a control variable in the automation system.

In this case, three temperatures of feed stream, equal to $250{ }^{\circ} \mathrm{C}, 300^{\circ} \mathrm{C}, 350^{\circ} \mathrm{C}$, and distillate temperature ranged from 110 to $170{ }^{\circ} \mathrm{C}$ were assumed in the process simulations. Number of theoretical stages also was a process variable.

Distillate was cooled to $20^{\circ} \mathrm{C}$ in the condenser-separator set and the light oil and gas were separated. The heavy oil was also cooled to $20^{\circ} \mathrm{C}$.

\section{Results and Discussion}

\section{Comparison of the Condensation and Fractionation Systems}

The results of process simulation of the three studied cases are presented in Figs. 8 and 9. The calculations were carried out for the vapour inlet stream at $300{ }^{\circ} \mathrm{C}$ and the three values of phase separation temperature $\left(110,140\right.$ and $\left.170{ }^{\circ} \mathrm{C}\right)$ corresponding to:

- TOWR-distillate temperature,

- 2 CNDR - outlet temperature from the first condenser,

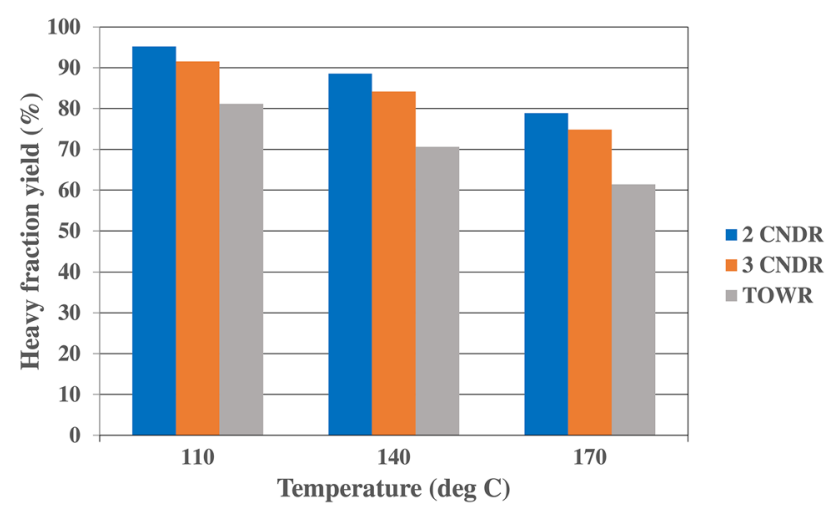

Fig. 8 The comparison of the three condensation and fractionation systems
- 3 CNDR-outlet temperature from the second condenser. Outlet temperature from the first condenser was equal to temperature of the bottom product from the adequate rectification column.

TOWR simulations were made for a column with 6 theoretical stages (including the partial condenser).

Figure 8 shows the ratio of the obtained heavy fraction stream to the total oil stream, defined as:

\section{Heavy fraction yield}

$$
\begin{aligned}
& =\frac{\text { Heavy fraction stream }}{(\text { Heavy fraction stream }+ \text { Light fraction stream })} \\
& \times 100 \%
\end{aligned}
$$

It is obvious that the increase of the separation temperature causes a reduction in the yield of heavy oil. For the same separation temperature, the highest efficiency of the heavy fraction is achieved for the simplest condensation system 2 CNDR. However, the composition of this fraction is also important.

The condensation systems were designed to fractionate the gas components from the pyrolysis reactor. After the preliminary studies, 7 compounds were selected for analyses. The content of these components in the light and heavy oil was sensitive to changes in the process parameters.

Figure 9 shows the fractionation of selected components in heavy fraction as a function of the phase separation temperature and the condensation system type. Component yield was defined analogously to the above-mentioned heavy fraction yield. The hydrocarbons bars are shown in the charts in order of increasing boiling point and flash point. As mentioned earlier, the separation of the pyrolytic oil into two fractions is aimed in increasing of the heavy fraction flash point. Therefore, it is essential to remove from this fraction the components with flash point below the limit value, which according to the standard was assumed of $56{ }^{\circ} \mathrm{C}$. In the case of model oil, hydrocarbons lighter than $n$-Undecane should be cut off (Table 1), which means the desired separation is between $\mathrm{n}$-Decane and $n$-Undecane.

In TOWR system satisfactory removal of n-Decane occurred at the separation temperature of $110^{\circ} \mathrm{C}$, while the 2 CNDR und 3 CNDR systems to achieve a similar effect should operate at a temperature significantly higher, at least $170{ }^{\circ} \mathrm{C}$. However, only in the case of TOWR light hydrocarbons were removed from heavy oil very efficiently, and no loss of heavy components was present.

As a result, comparing the cases of $110{ }^{\circ} \mathrm{C}$ TOWR and $170{ }^{\circ} \mathrm{C} 2 \mathrm{CNDR}$ with comparable heavy fraction yields about $80 \%$ (Fig. 8), one can see that for the TOWR 
Fig. 9 Fractionation of selected components in heavy fraction for separation temperatures equal to $110^{\circ} \mathrm{C}, 140{ }^{\circ} \mathrm{C}$ and $170{ }^{\circ} \mathrm{C}$
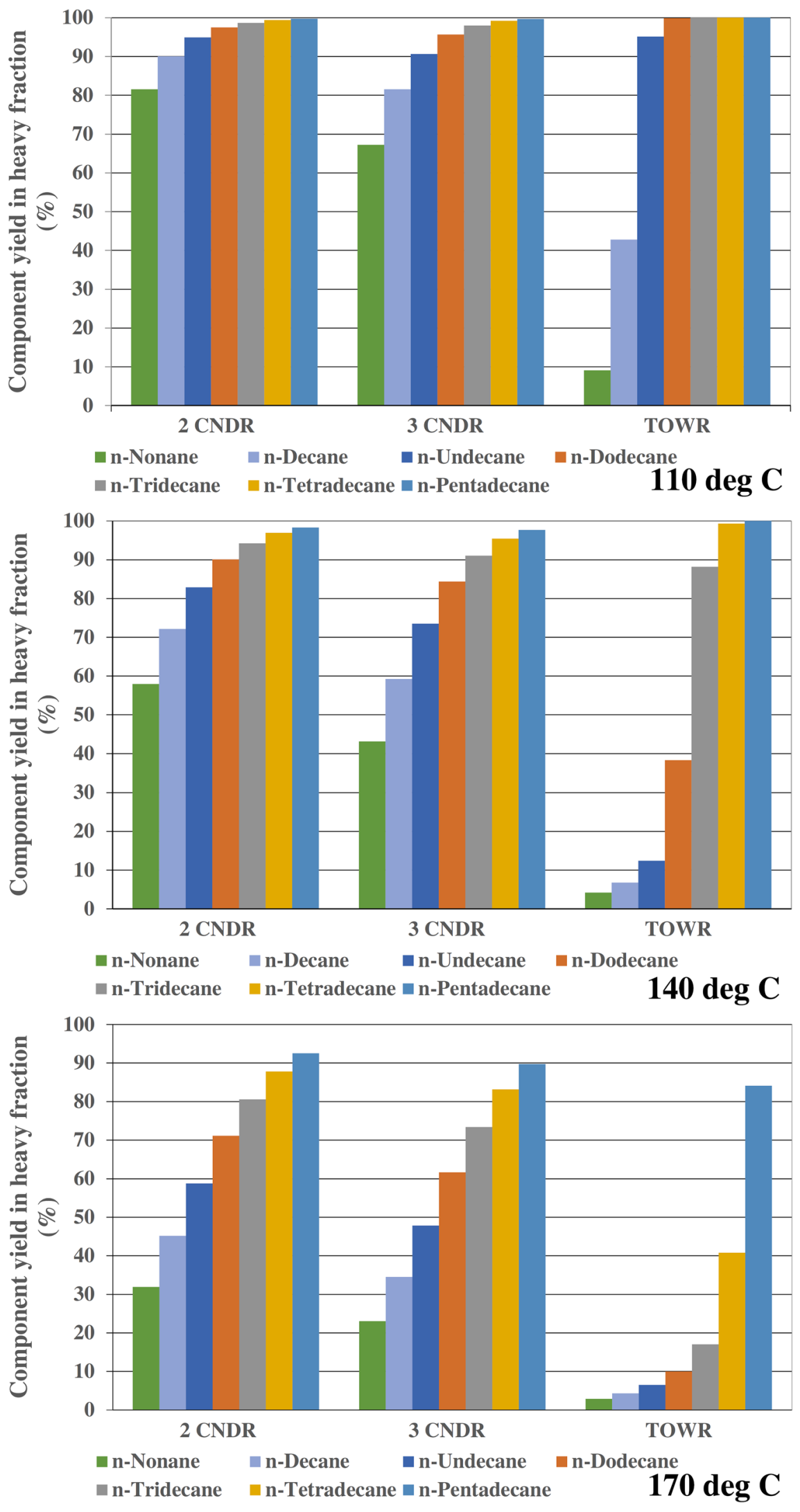


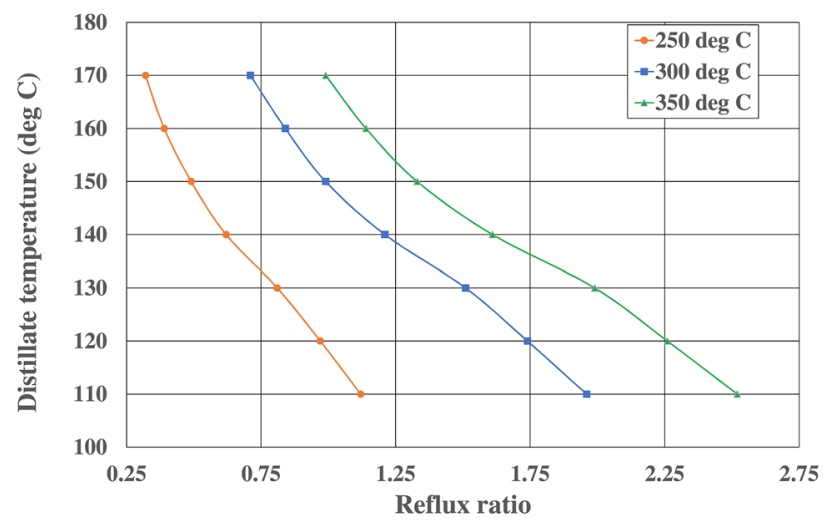

Fig. 10 Distillate temperature as a function of reflux ratio for different feed stream temperatures

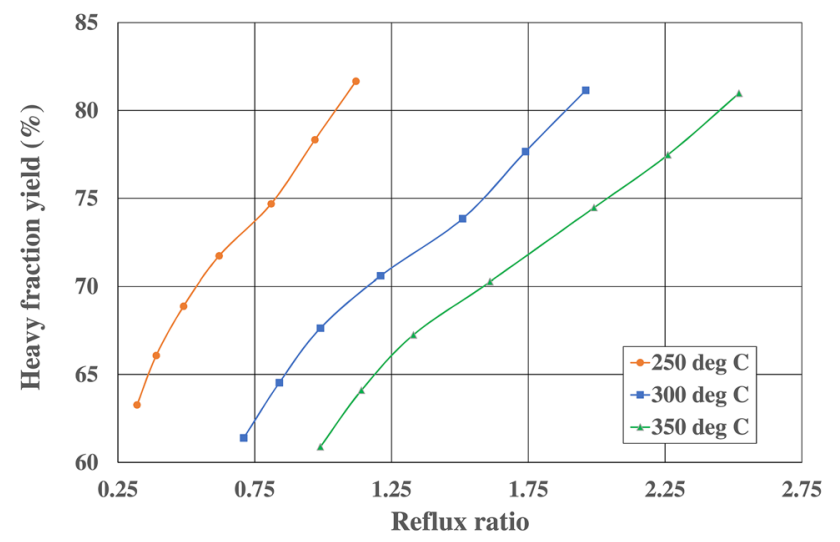

Fig. 11 Heavy fraction yield as a function of reflux ratio for different feed stream temperatures, TOWR 6 theoretical stages

configuration a much more favourable distribution of components was obtained (Fig. 9).

\section{TOWR Condensation and Fractionation System}

A detailed analysis of the TOWR condensation and fractionation system with the rectifying column was carried out. An inlet temperature, distillate temperature, number of stages and their efficiency were assumed as the independent process variables. As a result of the simulation, for each tested combination of input data a set of column and auxiliary devices (cooler, condenser, separator) operation parameters as well as outlet streams composition were calculated.

Both the inlet stream temperature and the assumed distillate temperature affect the reflux ratio, the heavy fraction yield and the heat exchanged in the condenser (Figs. 10, 11, 12).

At a fixed distillate temperature, the required reflux value strongly depends on the inlet temperature (Fig. 10). In order

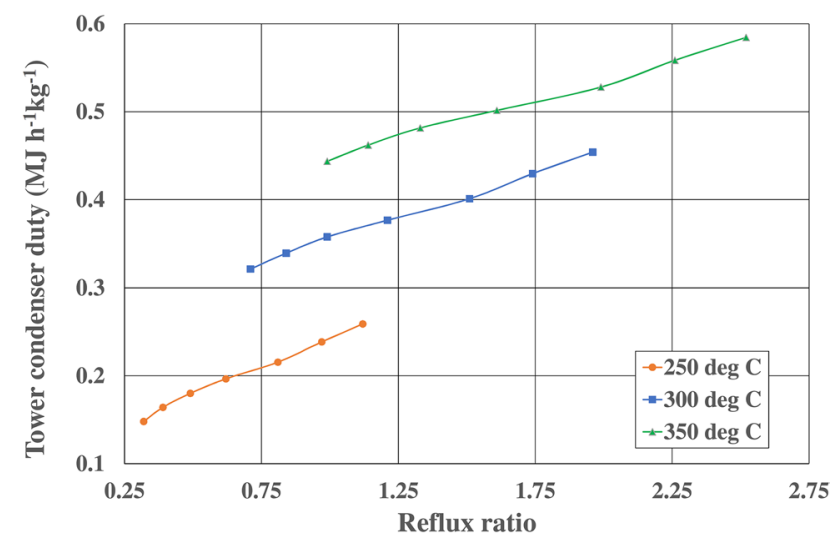

Fig. 12 Tower condenser duty per unit of feed stream mass as a function of reflux ratio for different feed stream temperatures

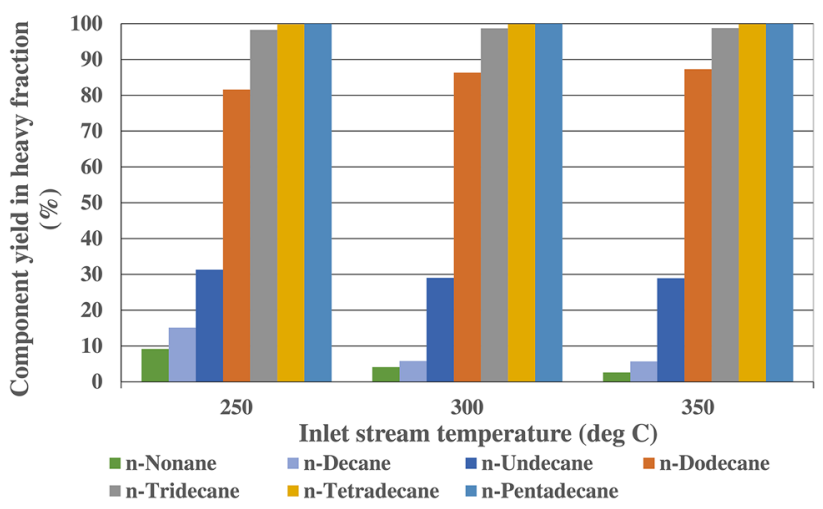

Fig. 13 Fractionation of selected components in heavy fraction as a function of feed stream temperature; distillate temperature $130^{\circ} \mathrm{C}, 10$ stages, Murphree tray efficiency $50 \%$

to keep the same temperature of the distillate, an increase in the inlet temperature of the feed stream requires an increase in the liquid flow in the column, and thus the reflux ratio.

There is also a correlation between the reflux ratio and the assumed distillate temperature. The higher required distillate temperature, the lower reflux value (Fig. 10), but also the lower productivity of the heavy product (Fig. 11).

As shown in Fig. 11, the inlet temperature has a negligible effect on the heavy fraction yield at the same distillate temperature.

The condenser heat duty is directly dependent on the inlet temperature and desired distillate temperature (Fig. 12). As mentioned above, the lower distillate temperature requires the higher reflux and thus the higher heat stream exchanged in the condenser. Similarly, the higher inlet temperature the higher heat duty.

Simulations indicated that the ratio of obtained fractions and their chemical composition can be changed by the reflux ratio controlling. The component distribution 
Fig. 14 Fractionation of selected components in heavy fraction as a function of theoretical stages number; feed stream temperature $300^{\circ} \mathrm{C}$, distillate temperature $150{ }^{\circ} \mathrm{C}$

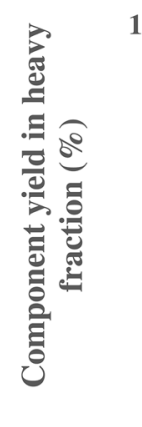

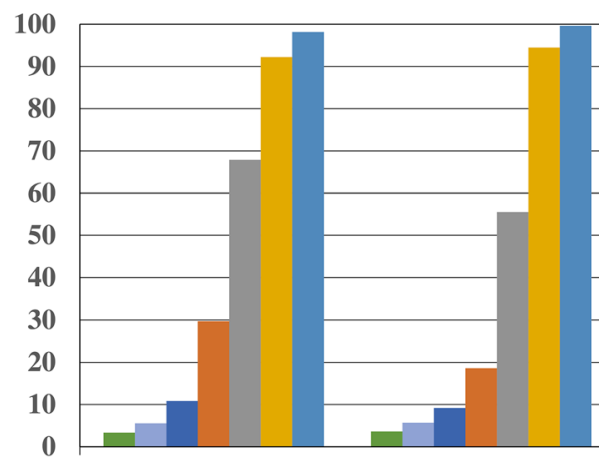

3

n-Nonane n-Tridecane
6

Number of theoretical stages

n-Decane $\quad$ n-Undecane
n-Tetradecane

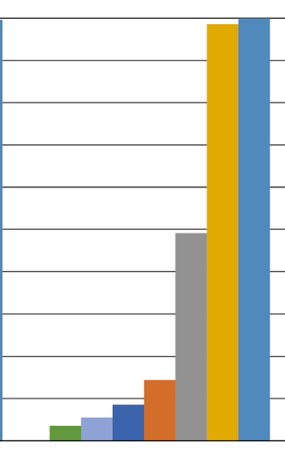

10

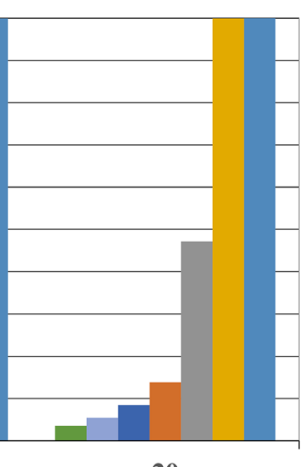

20

n-Dodecane between the two fractions changes significantly with the distillate temperature, regulated by the reflux ratio, as shown earlier in the Fig. 9. As can be seen from Fig. 13, the inlet stream temperature effect on heavy oil composition is negligible.

In the next part of the analysis of the TOWR system, the relationship between the number of stages and the distribution of the selected substances in the distillate and heavy liquid was examined.

The analysis was based on an inlet temperature of $300{ }^{\circ} \mathrm{C}$ and a distillate temperature of $150{ }^{\circ} \mathrm{C}$ (Fig. 14). The number of stages in column was assumed as $3,6,10$ and 20. The Murphree tray efficiency was set at $100 \%$, which corresponds to the efficiency of the theoretical stages.

It follows from the simulations that the number of stages affects the concentration of only 3-4 components of the model oil, in this case mainly $n$-dodecane and $n$-tridecane. The influence of the number of stages on the fractionation of substances with lower and higher boiling points is negligible.

The effect of the number of stages on the distribution of oil compounds is visible only at a low number of stages. Above 10 stages, further increase in the number practically does not affect the separation of components. In this system, there is no need to use a high-efficient column with a large number of stages.

In addition to global output data, ChemCad also allows for a detailed analysis of temperature distribution and stream compositions along the column.

For example, the Fig. 15 illustrates the profiles of temperature and mass streams of liquid and vapour along a column with 6 theoretical stages for the assumed inlet temperature of $300{ }^{\circ} \mathrm{C}$ and distillate temperature of $130{ }^{\circ} \mathrm{C}$ (reflux ratio 1.5). In addition, the Figs. 16 and 17 shows the mass flow of selected components in liquid and vapour at each stage. The stages are numbered from top to bottom, with the stage no. 1 being a partial condenser. The vapour from the partial

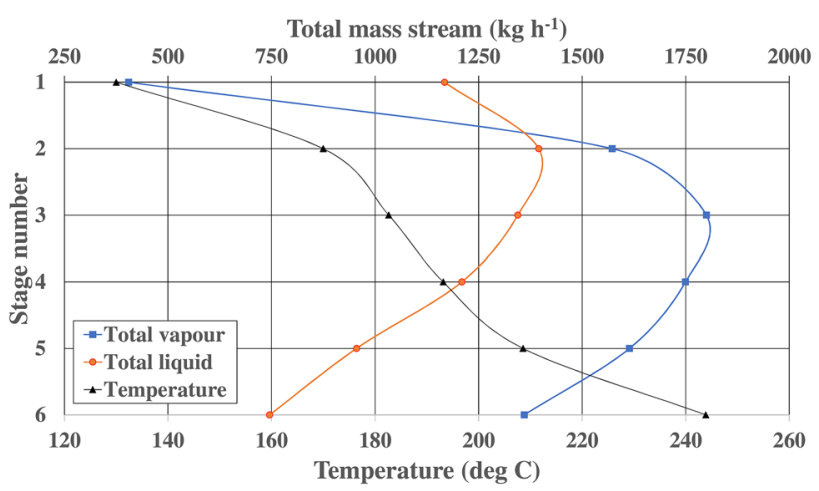

Fig. 15 Temperature and total mass flow profiles

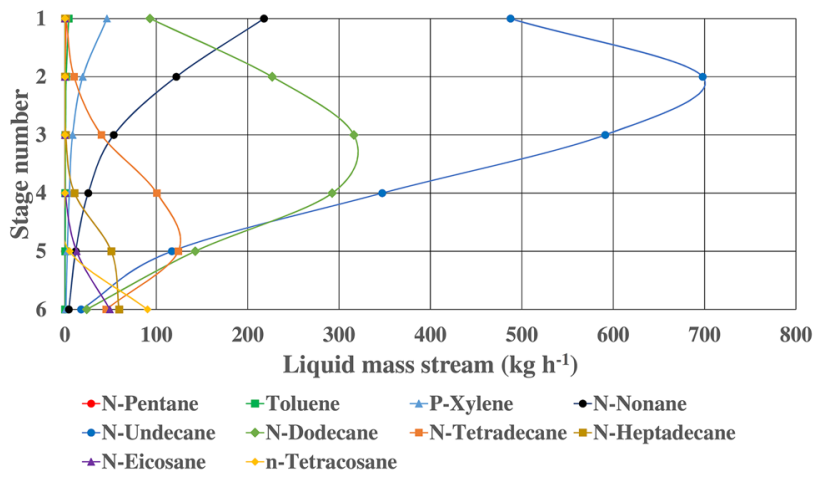

Fig. 16 Liquid composition profiles

condenser is defined as distillate and the liquid product as the reflux. The flow rate of a stage is specified as the mass flow rate leaving the stage. 


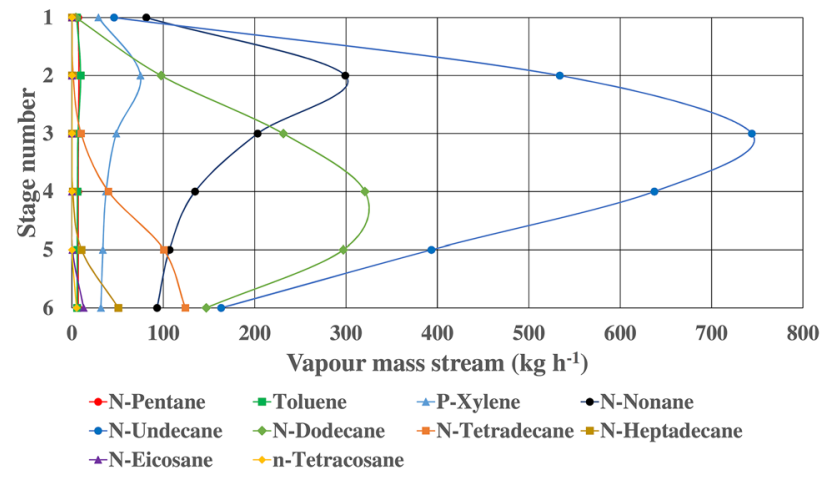

Fig. 17 Vapour composition profiles

The significant changes in the temperature profiles lead to corresponding large changes in the composition profiles. It can be seen in the profiles in Figs. 15 and 17 that the major shifts for the stage no. 1 are observed.

\section{Conclusions}

In this work, the analysis of various concepts of the condensation and fractionation unit of the waste plastics pyrolysis plant was carried out. A series of unit simulations were performed using ChemCad software. The pyrolytic oil from the industrial plant was used to determine the composition of the model feed stream. The effect of process parameters on heavy oil yield and composition was investigated.

It was shown that the equipment used in the condensation and fractionation system has an impact on the quality and quantity of oil products. Commonly used in industrial plants 3 CNDR system does not significantly improve the quality of oil products as compared to 2 CNDR system, while the use of a rectification column in TOWR system increases the fractions separation ability. The application of a column without a boiler gives a possibility to use the energy of hot post-pyrolytic gas.

The simulation of TOWR unit allows for the following conclusions:

- Reflux ratio, which determines the temperature of the distillate, is the main process parameter controlling the rectification column operation. By adjusting the reflux ratio, the composition and yield of oil fractions can be changed. As the reflux ratio increases the lower distillate temperature and higher heavy fraction yield is achieved.

- The temperature of the feed stream does not have a significant impact on the quality of the products. Thus, the TOWR unit is flexible and not sensitive to temperature fluctuations in the feed stream.
- The change in the number of stages has a significant impact on the composition of the oil fractions. Increasing the number of stages improves component separation, but this effect is significant only in the range of up to 10 stages. The benefits of increasing the number of stages above 10 are negligible, while the costs of building a higher rectification column increase significantly. It is not necessary to use a high-efficiency column with a large number of stages to achieve satisfactory results.

The proposed condensation and fractionation unit with the rectification column allows for accurate control of both oil fractions composition by changing the process parameters. However, TOWR configuration is more sophisticated compared to the system of heat exchangers and needs higher technical requirements during operation and periodic cleaning.

Acknowledgements The authors are grateful to The Nacional Centre of Research and Development (project no. POIR 1.2 PBSE/2016) and the Division of Separation Processes and Chair of Engineering Integrated Process, Faculty of Chemical and Process Engineering, Warsaw University of Technology for their financial support.

\section{Compliance with Ethical Standards}

Conflict of interest The authors declare that they have no competing interests.

Open Access This article is licensed under a Creative Commons Attribution 4.0 International License, which permits use, sharing, adaptation, distribution and reproduction in any medium or format, as long as you give appropriate credit to the original author(s) and the source, provide a link to the Creative Commons licence, and indicate if changes were made. The images or other third party material in this article are included in the article's Creative Commons licence, unless indicated otherwise in a credit line to the material. If material is not included in the article's Creative Commons licence and your intended use is not permitted by statutory regulation or exceeds the permitted use, you will need to obtain permission directly from the copyright holder. To view a copy of this licence, visit http://creativecommons.org/licenses/by/4.0/.

\section{References}

1. PlasticsEurope: Plastics-the Facts 2018. https://www.plast icseurope.org/pl/resources/publications/619-plastics-facts-2018 (2018). Accessed 8 Apr 2019

2. Butler, E., Devlin, G., McDonnell, K.: Waste polyolefins to liquid fuels via pyrolysis: review of commercial state-of-the-art and recent laboratory research. Waste Biomass Valoriz. 2(3), 227-255 (2011). https://doi.org/10.1007/s12649-011-9067-5

3. Fox, J.A., Stacey, N.T.: Process targeting: an energy based comparison of waste plastic processing technologies. Energy 170, 273-283 (2018). https://doi.org/10.1016/j.energy.2018.12.160

4. Okan, M., Aydin, H.M., Barsbay, M.: Current approaches to waste polymer utilization and minimization: a review. J. Chem. 
Technol. Biotechnol. 94, 8-21 (2019). https://doi.org/10.1002/ jctb.5778

5. Siddiqui, M.N., Redhwi, H.H.: Pyrolysis of mixed plastics for the recovery of useful products. Fuel Process. Technol. 90, 545-552 (2009). https://doi.org/10.1016/j.fuproc.2009.01.003

6. Sharuddin, S.D.A., Abnisa, F., Daud, W.M.A.W., Aroua, M.K.: A review on pyrolysis of plastic wastes. Energy Convers. Manage. 115, 308-326 (2016). https://doi.org/10.1016/j.encon man.2016.02.037

7. Miandad, R., Barakat, M.A., Aburiazaiza, A.S., Rehan, M., Ismail, I.M.I., Nizami, A.S.: Effect of plastic waste types on pyrolysis liquid oil. Int. Biodeter. Biodegr. 119, 239-252 (2017). https://doi.org/10.1016/j.ibiod.2016.09.017

8. Singh, R.K., Ruj, B., Sadhukhan, A.K., Gupta, P.: Thermal degradation of waste plastics under non-sweeping atmosphere: part 1: effect of temperature, product optimization, and degradation mechanism. J. Environ. Manage. 239, 395-406 (2019). https:// doi.org/10.1016/j.jenvman.2019.03.067

\section{Affiliations}

\section{Roman Krzywda $^{1}$ (D) Bogumiła Wrzesińska ${ }^{1}$}

Bogumiła Wrzesińska

Bogumila.Wrzesinska@pw.edu.pl
9. Chandran, M., Tamilkolundu, S., Murugesan, C.: Characterization studies: waste plastic oil and its blends. Energy Source A (2019). https://doi.org/10.1080/15567036.2019.1587074

10. Walendziewski, J.: Engine fuel derived from waste plastics by thermal treatment. Fuel 81, 473-481 (2002)

11. Bezergianni, S., Dimitriadis, A., Faussone, G.-C., Karonis, D.: Alternative diesel from waste plastics. Energies 10, 1750 (2017). https://doi.org/10.3390/en10111750

12. Wiriyaumpaiwong, S., Jamradloeduk, J.: Distillation of pyrolytic oil obtained from fast pyrolysis of plastic wastes. Energy Procedia 138, 111-115 (2017). https://doi.org/10.1016/j.egypr o.2017.10.071

13. Stephenson, R.M.: Flash Points of Organic and Organometallic Compounds. Elsevier Science Publishing, New York (1987)

Publisher's Note Springer Nature remains neutral with regard to jurisdictional claims in published maps and institutional affiliations.

1 Faculty of Chemical and Process Engineering, Warsaw University of Technology, ul. Waryńskiego 1, 00-645 Warsaw, Poland 